\title{
ПЛ-9 \\ ОСОБЕННОСТИ ПРОБОПОДГОТОВКИ И ОПРЕДЕЛЕНИЯ СОДЕРЖАНИЯ РТУТИ В РАЗЛИЧНЫХ ОБЪЕКТАХ ОКРУЖАЮЩЕЙ СРЕДЫ
}

\author{
Эйрих С.С.
}

Институт водных и экологических проблем Сибирского отделения РАН, Барнаул, Россия

steyrikh@gmail.com

DOI: 10.26902/ASFE-11_10

Несмотря на то, что ртуть является рассеянным элементом, она обнаруживается во всех компонентах окружающей среды, распространяясь на локальном, региональном и глобальном уровнях. Ртуть является высокотоксичным веществом и, обладая способностью к бионакоплению и биомагнификации по трофической цепи, негативно влияет на наземные и водные экосистемы и человека. Химические и физические свойства ртути обусловливают ее высокую подвижность в окружающей среде, разнообразие существующих форм и перераспределение между ними в зависимости от условий среды

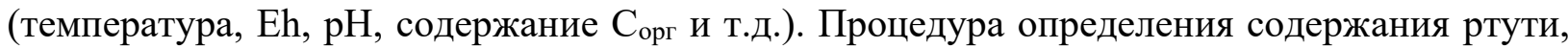
используемые аналитические методы и подходы определяются формой ее нахождения и типом объекта окружающей среды.

Достоверное определение содержания ртути зависит не только от инструментального определения, но и от всех стадий анализа, начиная с пробоотбора и заканчивая представлением результатов анализа с оценкой их прецизионности. В докладе будут рассмотрены проблемы и сложности, возникающие на различных стадиях анализа, такие как возможные изменения состава пробы вследствие ее транспортировки и хранения, неполнота извлечения, адсорбция на стенках посуды либо загрязнение пробы при пробоподготовке, матричные эффекты и неоднородность состава. Особое внимание следует уделять подготовке посуды, контролю реактивов и всей процедуры пробоподготовки, транспортировки и анализа с использованием холостых проб (методических, лабораторных, полевых). В зависимости от анализируемого объекта та или иная стадия может быть наиболее критической. Так, если для слабоминерализованных вод, атмосферных осадков и кернов льда наиболее важно обеспечение ультрачистых условий и высокочувствительных методов анализа, то для таких консервативных сред, как породы, грунты и почвы - гомогенизация образца и устранение влияния основы.

В докладе также подчеркивается важность выбора адекватных методов анализа и проверка их правильности, оценка предела обнаружения и возможности его снижения. В докладе рассмотрены основные принципы программы по обеспечению и контролю качества аналитических данных (QA/QC quality assurance/quality control) и процедуры контроля, необходимые в каждой серии определений. Для контроля правильности используют метод добавок, анализ соответствующих стандартных образцов известного состава (CRM природных вод, донных отложений, почв, волос и других объектов) и сопоставление результатов, полученных разными методами. Решающая роль при оценке правильности аналитических работ принадлежит межлабораторным сравнительным испытаниям (интеркалибрации).

Обзор используемых методов определения ртути и рекомендации, основанные на многолетнем опыте автора, будут полезны для практического использования при анализе различных объектов окружающей среды. 